\title{
Regulation of ERK3/MAPK6 expression by BRAF
}

\author{
KLAUS P. HOEFLICH ${ }^{1}$, MICHAEL T. EBY ${ }^{1}$, WILLIAM F. FORREST ${ }^{2}$, DANIEL C. GRAY ${ }^{1}$, \\ JANET Y. TIEN ${ }^{3}$, HOWARD M. STERN ${ }^{4}$, LESLEY J. MURRAY ${ }^{3}$, DAVID P. DAVIS ${ }^{1}$, \\ ZORA MODRUSAN $^{1}$ and SOMASEKAR SESHAGIRI ${ }^{1}$
}

\begin{abstract}
Departments of ${ }^{1}$ Molecular Biology, ${ }^{2}$ Biostatistics, ${ }^{3}$ Translational Oncology, and ${ }^{4}$ Molecular Diagnostics, Genentech, 1 DNA Way, South San Francisco, CA 94080, USA
\end{abstract}

Received May 2, 2006; Accepted June 26, 2006

\begin{abstract}
Several forms of cancer are characterized by frequent activating mutations in the serine/threonine kinase, BRAF. Substitution of glutamic acid for valine at codon 600 (V600E) accounts for approximately $90 \%$ of all BRAF activating mutations and leads to stimulation of kinase activity, downstream signaling, and cell transformation. To better understand the molecular pathogenesis induced by oncogenic BRAF signaling, we used microarray gene expression profiling to comprehensively analyze the BRAF-directed transcriptional program of cells expressing a conditionally active form of BRAF $^{\mathrm{V} 600 \mathrm{E}}$. Several novel genes that affect proliferation, cell survival, angiogenesis and immune surveillance were identified as possible mediators of BRAF-induced oncogenic signaling. Moreover, we show that a MAPK family member, extracellular signal-regulated kinase-3 (ERK3/MAPK6) is highly expressed in response to BRAF signaling in this system. Cellular ERK3 protein is highly unstable and pharmacological inhibition of BRAF activity resulted in rapid ERK3 degradation. In melanoma cells, RNAi-mediated knockdown of endogenous BRAF or treatment with MEK inhibitors that prevent ERK1/2 activation led to a reduction in ERK3 levels, indicating that elevated ERK3 expression is mediated through MEK1/2 signaling. These results provide strong evidence for another mode by which BRAF can regulate the ERK protein kinase family and suggest ERK3 to be a potential pharmacodynamic marker for targeting BRAF signaling in melanoma.
\end{abstract}

\section{Introduction}

The incidence of melanoma has increased steadily during the last decade. In the United States, approximately 60,000 new cases of melanoma are diagnosed annually and an estimated 7,700 patients will die of melanoma in 2005 (1). Despite improvements in early detection of the disease, malignant

Correspondence to: Dr Somasekar Seshagiri, Department of Molecular Biology, Genentech Inc., 1 DNA Way MS224, South San Francisco, CA 94080, USA

E-mail: sekar@gene.com

Key words: serine/threonine kinase, BRAF, MAPK family melanoma is highly resistant to traditional cancer treatments and there is a significant unmet medical need for the development of effective therapies that can stabilize or slow its progression (2). A recent beacon of hope in the treatment of melanoma has been the observation that somatic BRAF mutations have been identified to occur with very high frequency in atypical melanocytic nevi and early stage melanoma $(3,4)$. Almost $90 \%$ of these BRAF mutations are a T1799A transversion in exon 15 that results in a $\mathrm{Val}^{600} \mathrm{Glu}$ (V600E) amino acid substitution in the activation segment of the kinase $(5,6)$. This mutation obviates the requirement for the T599 and S602 phosphorylation that occurs during normal BRAF activation and leads to constitutive kinase activity. In light of this, several groups are actively engaged in developing therapeutic agents to target BRAF or its downstream kinases, with BAY 43-9006 being furthest along in clinical testing $(7,8)$.

BRAF elicits activation of MEK $1 / 2$ and extracellular signal-regulated kinases $1 / 2$ (ERK1/2) $(4,9)$. There are more than 70 described ERK1/2 substrates that involve a multitude of cellular responses relevant to tumorigenesis, including cell proliferation, invasion, survival and angiogenesis $(10,11)$. While ERK1/2 function and signaling have been studied extensively, considerably less is known about other ERK family members, including ERK3/MAPK6 (12). ERK3 is a $97 \mathrm{kDa}$ protein that shares $\sim 50 \%$ identity with ERK1 in its kinase domain $(13,14)$. Although ERK3 is thought to be compatible with kinase activity, putative in vivo substrates are still controversial $(15,16)$. ERK3 possesses two striking biochemical features within the kinase domain that distinguishes it from the other ERK family members. Firstly, ERK3 contains a Ser-Glu-Gly sequence in place of the canonical Thr-Xaa-Tyr phosphorylation motif found in other ERK family members that is essential for MAPK activation and substrate binding. Furthermore, the Ala-Pro-Glu activation loop motif that stabilizes the C-terminal lobe of typical protein kinases (17) is also not conserved in ERK3. Although the phosphorylation-mediated regulation of ERK3 is currently not well under-stood, insight into an additional level of ERK3 regulation ensued from the identification of this kinase in a microarray screen for genes with increased expression following treatment with proteosome inhibitors (18). Further studies showed that ERK3 protein is rapidly degraded by the ubiquitin-proteosome pathway and this appears to be an important mechanism for regulating ERK3 
levels in vivo (19). An ERK3-binding partner, MAPKactivated protein kinase-5, has also been shown to stabilize endogenous levels of ERK3 $(15,16)$. Taken together, this suggests that the biological activity of ERK3 is largely regulated by its cellular abundance through control of mRNA and/or protein synthesis and stability.

Given the importance of the BRAF signaling pathway in biology and medicine, we have undertaken a study to characterize the downstream signaling and gene expression changes elicited by oncogenic BRAF at a scope not demonstrated previously. Using inducible-BRAF cell lines coupled with global microarray profiling and molecular network analysis, novel targets of the BRAF-MEK1/2-ERK1/2 pathway have been identified. In particular, we herein validate the MAPK family gene, ERK3, as a transcriptional target of BRAF that is frequently elevated in tumors with activating BRAF missense mutations.

\section{Materials and methods}

Reagents. NIH 3 T3 and A375 cells (American Type Culture Collection) were maintained at $37^{\circ} \mathrm{C}$ and $5 \% \mathrm{CO}_{2}$ in DMEM or RPMI-1640 media with $10 \%$ fetal bovine serum, $4 \mathrm{mM}$ L-glutamine and penicillin-streptomycin. Antibodies used for immunoblotting were as follows: anti-ERK2, anti-p-ERK1/2 (Thr202/Tyr204), anti-ERK3, anti-MAPKAPK2 (Cell Signaling Technology); anti-BRAF (F-7; Santa Cruz Biotechnology); and horseradish peroxidase-conjugated secondary antibodies (Pierce Biotechnology). U0216 and anisomycin were purchased from Cell Signaling Technology and Sigma, respectively. Quantification of murine ERK3 mRNA levels was performed by TaqMan analysis (Applied Biosystems) with 5'-GTA ACA AGA GTA TGT GGC AAA ACA-3', 5'-ACA ATA AAC GCT GGC TAA ATA GAA-3' and 5'FAM ATA CCA CCC ATA GTG CTT CAC AAA ATG CAC TAMRA-3' primers. ERK3-specific siRNAs used were as follows: ERK3 siRNA-1 (sense) 5'-CUA CUG AUG UUG UUG AUA AUU-3' and ERK3 siRNA-2 (sense) 5'-CUG AAG GAU UGG UUA CUA AUU-3'.

Inducible shRNA constructs. Hairpin oligonucleotides used in this study are as follows: BRAF shRNA (sense) 5'-GAT CCC CAG AAT TGG ATC TGG ATC ATT TCA AGA GAA TGA TCC AGA TCC AAT TCT TTT TTT GGA AA-3', BRAF shRNA-1 (antisense) 5'-AGC TTT TCC AAA AAA AGA ATT GGA TCT GGA TCA TTC TCT TGA AAT GAT CCA GAT CCA ATT CTG GG-3', Luciferase shRNA (sense) 5'-GAT CCC CCT TAC GCT GAG TAC TTC GAT TCA AGA GAT CGA AGT ACT CAG CGT AAG TTT TTT GGA AA-3', Luciferase shRNA (antisense) 5'-AGC TTT TCC AAA AAA CTT ACG CTG AGT ACT TCG ATC TCT TGA ATC GAA GTA CTC AGC GTA AGG GG-3', ERK3 shRNA (sense) 5'-GAT CCC CCC TAC TGA TGT TGT TGA TAT TCA AGA GAT ATC AAC AAC ATC AGT AGG TTT TTT GGA AA-3', ERK3 shRNA (antisense) 5'-AGC TTT TCC AAA AAA CCT ACT GAT GTT GTT GAT ATC TCT TGA ATA TCA ACA ACA TCA GTA GGG GG-3'. The complementary double-stranded shRNA oligos were inserted into our tetracycline-inducible retrovirus gene transfer vector using BglII and HindIII restriction enzyme sites (20). Our vector system is comprised of a kanamycin-resistant, H1 promoter-driven shRNA expression shuttle plasmid and an ampicillin-resistant retroviral vector backbone that contains a codon-optimized TetR-IRES-puromycin cassette to enable Tet-regulated shRNA expression. Knockdown vectors are constructed by cloning shRNA oligos into the shuttle vector followed by a Gateway recombination reaction (Invitrogen) to transfer the shRNA cassette in the retroviral vector. All constructs were verified by sequencing. Gene knockdown using these shRNAs was first verified in transient assays.

Generation of stable cell lines. Wild-type or oncogenic (V600E) BRAF kinase domains (amino acids 413-765) were ligated to the murine hormone-binding domain of the murine estrogen recepter (ER; amino acids 281-599 containing a G525R mutation). This chimera was cloned into the pLNCX2 retroviral vector (BD Clontech). Viruses were produced using PT76 cells (BD Clontech) and target NIH 3T3 cells were selected with G418 for 2 weeks. Stable clones were expanded and tested for 4-hydroxytamoxifen-induced BRAF signaling by immunoblotting.

For inducible-shRNA A375 clones, retroviral infection was performed using Phoenix packaging cells according to the manufacturer's instructions (Orbigen). As the puromycinresistance gene encoded in the vector is under the control of a constitutive $\beta$-actin promoter, $5 \mu \mathrm{g} / \mathrm{ml}$ puromycin was used to select infected cells expressing shRNA. Stable clones were isolated, treated with $1 \mathrm{mg} / \mathrm{ml}$ doxycycline (BD Clontech) for 3 days, and endogenous BRAF knockdown assessed by quantitative RT-PCR. Clones were further characterized for changes in BRAF protein expression and p-ERK1/2 status.

Microarray analysis and statistical methods. NIH 3T3 control vector, $\triangle B R A F$ :ER and $\triangle \mathrm{BRAF}^{\mathrm{V} 600 \mathrm{E}}$ :ER cell lines were grown in phenol red-free Dulbecco's modified Eagle's medium supplemented with $10 \%$ charcoal-filtered fetal bovine serum, penicillin-streptomycin and L-glutamine. For stimulations, cells were pre-incubated overnight in minimal media containing $0.5 \% \mathrm{FBS}, 0.5 \mathrm{mg} / \mathrm{ml}$ bovine serum albumin and insulintransferrin-selenium supplement (ITS-X; Invitrogen) prior to treatment with 4-hydroxytamoxifen (4OHT; Sigma) for $24 \mathrm{~h}$. Total RNA was isolated using the RNeasy RNA isolation kit (Qiagen) from at least 2 independent cell cultures grown in the presence or absence of 4OHT. Complementary DNA was synthesized and hybridized to an Affymetrix Mouse430v2 chip. For each of the 45,101 probe sets an analysis of variance (ANOVA) was applied to Affymetrix Microarray Suite (MAS) version 5.0 signal data to estimate the expression and accompanying variability for each of the treatment groups. Cells treated with the solvent (ethanol) and cultured in minimal medium were used as a control. Furthermore, to rule out effects of 4OHT, RNA from vector-infected $3 \mathrm{~T} 3$ cells treated with $50 \mathrm{nM} 4 \mathrm{OHT}$ was also compared as a control experiment. The probe set was assigned a rank based on the weight of evidence for simultaneous change in both $\triangle B R A F: E R$ and $\triangle B \mathrm{BF}^{\mathrm{V}}{ }^{600 \mathrm{E}}$ :ER cell lines. Additionally, fold change estimates and accompanying confidence intervals of the 4OHT treated cultures versus the untreated cultures were computed and recorded for the cell lines. All computations were performed on the logarithmic scale. The Benjamini and Hochberg false 
discovery rate was applied as a multiple test correction. Gene ontologies were assigned using the information provided by the Gene Ontology Consortium (http://www.geneontology. org). Analysis of molecular networks was performed using the web-based entry tool developed by Ingenuity Systems Inc. (www.ingenuity.com).

Xenograft models. Six- to 8-week-old female athymic nu/nu mice were purchased from Charles River Laboratories and maintained in our institute's conventional animal facility. For subcutaneous tumor models, mice were injected in the right flank with $1 \times 10^{7}$ human A375 shRNA-containing cell clones resuspended into $200 \mu \mathrm{l}$ phosphate-buffered saline (PBS). When tumors reached a mean volume of $150-200 \mathrm{~mm}^{3}$ the mice with similarly sized tumors were grouped into treatment cohorts. Mice received 5\% sucrose only or 5\% sucrose plus $1 \mathrm{mg} / \mathrm{ml}$ doxycycline for control and knockdown cohorts, respectively. All water bottles were changed 3 times per week. Tumors were measured with calipers and mice weighed twice per week. Between 7-10 mice were used for each treatment group and results are presented as mean tumor volume \pm SEM. Following 2, 4 or 6 days of shRNA induction, tumor samples were collected.

Immunohistochemistry. Formalin-fixed, paraffin-embedded specimens were collected and a routine hematoxylin and eosin slide was first evaluated. IHC staining was performed on 5- $\mu \mathrm{m}$-thick paraffin-embedded sections using anti-Ki-67 (clone MIB-1, mouse anti-human with the Dako ARC Kit), anti-panendothelial cell marker (clone MECA-32, monoclonal rat anti-mouse), and anti-cleaved caspase-3 (rabbit anti-human and anti-mouse) antibodies with a standard avidin-biotin HRP detection system according to the manufacturer's instructions. Tissues were counterstained with haematoxylin, dehydrated, and mounted. In all cases, antigen retrieval was performed with the Dako Target Retrieval Kit as per manufacturer's instructions.

Western blot analysis. Cells were lysed in modified RIPA buffer containing $50 \mathrm{mM}$ Tris $\mathrm{pH} 7.4,150 \mathrm{mM} \mathrm{NaCl}, 1 \mathrm{mM}$ EDTA, 1\% Brij-35, 0.1\% deoxycholate, protease inhibitors (Roche Molecular Biochemicals) and phosphatase inhibitor cocktail (Sigma). SDS-PAGE (4-12\% gel) was used to resolve the proteins in the lysate. After electrophoresis, the proteins were electrotransferred onto a polyvinylidene fluoride microporous membrane and immunodetected using standard procedures.

\section{Results}

Characterization of the BRAF-regulated transcriptome. To identify genes that are regulated specifically in response to BRAF activation and not as a result of full mitogenic stimulation, we employed the previously described estrogen receptor (ER) fusion protein system to achieve conditional activation of BRAF (21). NIH 3T3 cells expressing the catalytic domains of wild-type and oncogenic human BRAF (denoted as $\triangle B R A F$ and $\triangle B R A F^{V 600 E}$, respectively) were derived by retroviral infection and several independent clones were characterized to ensure against a clonal selection bias (data not shown). Gene expression profiles from quiescent $\triangle B R A F: E R$, $\triangle \mathrm{BRAF}^{\mathrm{V} 600 \mathrm{E}}$ :ER and control cells cultured in minimal media, untreated or treated with $50 \mathrm{nM} 4 \mathrm{OHT}$ for $24 \mathrm{~h}$ to activate BRAF chimeric proteins, were examined using Affymetrix whole genome oligonucleotide microarrays. Analysis of variance (ANOVA) was performed to estimate the expression and accompanying variability for each of the probe sets across treatments. To rule out effects of tamoxifen, RNA from vectorinfected $3 \mathrm{~T} 3$ cells treated with $50 \mathrm{nM} 4 \mathrm{OHT}$ was compared as a control experiment. Of a total of 45,101 probe sets, 3176 probes showed differential expression upon 4OHT treatment concomitantly in both $\triangle \mathrm{BRAF}: \mathrm{ER}$ and $\triangle \mathrm{BRAF}^{\mathrm{V} 600 \mathrm{E}}$ :ER cell lines but not in control infected cells. Numerous genes identified in our screen are established immediate-early transcriptional targets of RAF-MEK-ERK1/2 signaling $(22,23)$. Furthermore, expression of ERK1/2 pathway negative-feedback regulators, such as MAPK phosphatase-3 and Spred/ Sprouty, are also up-regulated as expected (data not shown) and thereby validate both the cell system and the microarray analysis.

Validation of genes differentially expressed by oncogenic $B R A F$. To prioritize the differentially expressed genes, ontologies were assigned using the information provided by the Gene Ontology Consortium (24). We focused our attention on those genes that are components of cellular activities associated with BRAF signaling or known to contribute to cell transformation and tumorigenesis (Fig. 1A). For instance, positive feedback signaling for the RAF-MEK-ERK1/2 pathway was underscored by the BRAF-dependent increase in transcription of epidermal growth factor (EGF) family ligands. Expression changes were approximately 30- to 200-fold for B-cellulin (BTC), epiregulin (ERG) and heparin-binding EGF (HB-EGF) as confirmed by real-time quantitative PCR (qPCR; Fig. 1B). Apart from the EGF family ligands, we also observed a 10-fold increase in brain-derived neurotrophic factor (BDNF) transcription in response to BRAF activity (Fig. 1B). Given the neuronal phenotype of BRAF-deficient mouse embryos, in which functional BRAF is required for sensory and motoneurons to respond to BDNF-induced survival signals (25), this transcriptional feedback mechanism may be critical for BRAF-mediated neuronal viability.

For the first time, we demonstrate expression of Semaphorin $7 \mathrm{a}$ and Slit2, members of extracellular protein families that function both in guiding somatic cell migration and in promoting tumor-induced angiogenesis, to be elevated in response to increased BRAF activity (26). Furthermore, genes that belong to the interleukin (IL) family were both positively and negatively regulated by BRAF signaling, as shown for pleiotropic cytokines IL-11 and IL-18, respectively (Fig. 1B). This would suggest immunoregulatory functions for BRAF. Interestingly, in addition to its secretion by activated macrophages, Kupffer cells, dendritic cells, Langerhans cells and B cells, IL-18 is also produced by epithelial cells of the skin, gastrointestinal tract, and the airway (27). In this capacity, IL-18 has been implicated in the host immune defense against tumor development. Hence, it can be hypothesized that by limiting IL-18 production, oncogenic BRAF may promote initiation and maintenance of tumor growth via evasion of the host immune system. 
A

Cell Proliferation
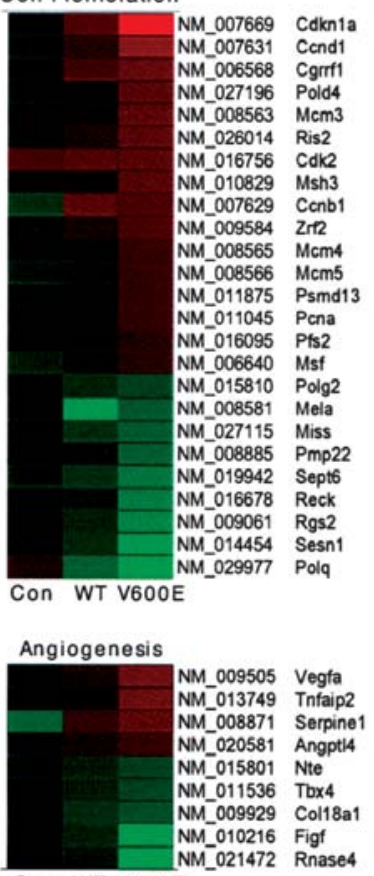

Con WT V600E

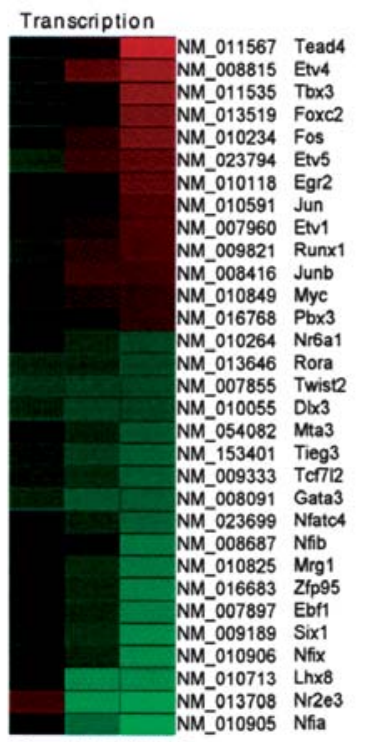

Con WT V600E

\section{Apoptosis}

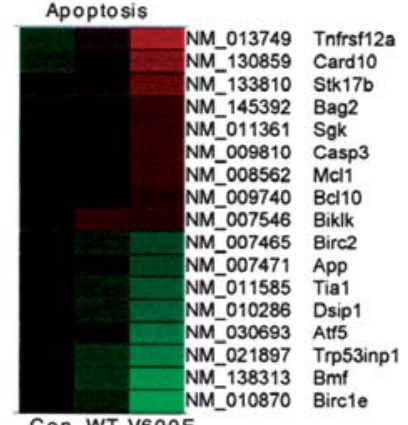

Con WT V600E
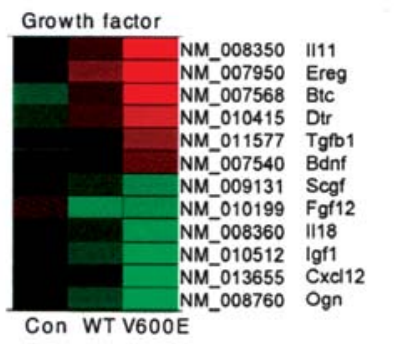

Phosphorylation

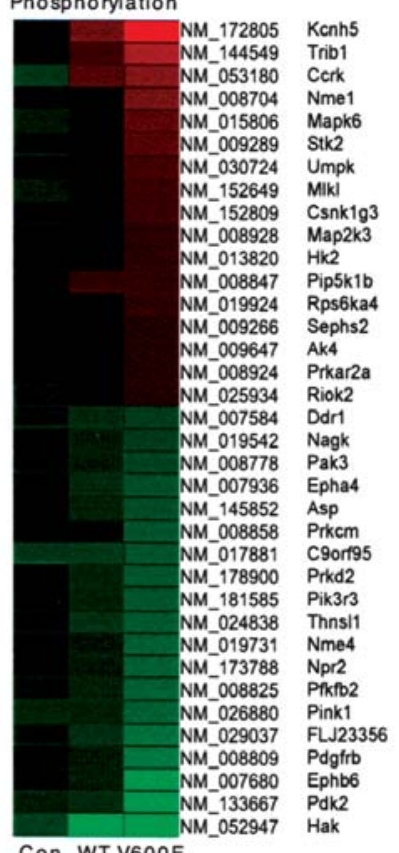

B
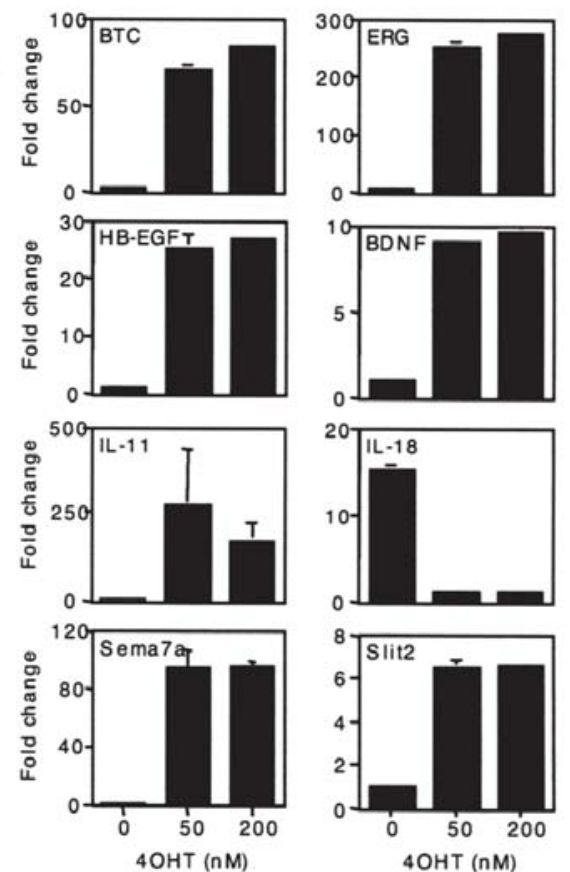

\section{C}
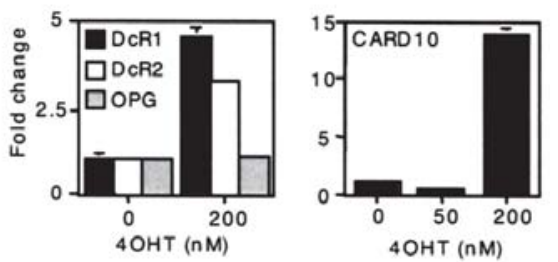

Figure 1. Genes with altered expression upon $\triangle \mathrm{BRAF}$ :ER and $\triangle B R A F^{\mathrm{V} 600 \mathrm{E}}$ :ER induction. (A), Expression profiles of genes with $>2$-fold change in response to BRAF activation. Functional categories were assigned according to information retrieved from the Gene Ontology Consortium. Red color represents increased transcription following 4OHT treatment, while the green color represents decreased expression. The standardized expression values for each gene are displayed in a $\log _{2}$ scale. (B), Real-time quantitative PCR (qPCR) validation of genes showing BRAF ${ }^{\mathrm{V} 600 \mathrm{E}}$-mediated differential expression. To confirm microarray hybridization intensity values, $\triangle B R A F^{\mathrm{V} 600 \mathrm{E}}$ : ER cells were treated with the indicated 4-hydroxytamoxifen (4OHT) concentrations for $24 \mathrm{~h}$. RNA was prepared and subject to TaqMan qPCR analysis. Data are represented as fold increase over unstimulated controls and were normalized to RPL19 mRNA. BTC, ß-cellulin; ERG, epiregulin; HB-EGF, heparin-binding epidermal growth factor; IL-11, interleukin-11; IL-18, interleukin-18; BDNF, brain-derived neurotrophic factor;

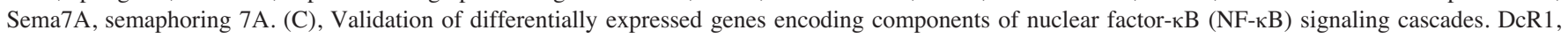
decoy receptor 1; DcR2, decoy receptor 2; OPG, osteoprotegerin; CARD10, caspase recruitment domain 10.

There were changes in the expression of genes encoding components of signaling cascades that regulate activation of nuclear factor- $\kappa \mathrm{B}(\mathrm{NF}-\kappa \mathrm{B})$, a transcription factor that controls many processes including immunity, inflammation and apoptosis. In support of this, BRAF ${ }^{600 E}$ mutation has been previously shown to activate $\mathrm{NF}-\kappa \mathrm{B}$ in an IKKß-dependent manner in NIH 3 T3 cells (28). Our expression analysis demonstrated that induction of $\mathrm{BRAF}^{\mathrm{V} 600 \mathrm{E}}$ resulted in a 15 -fold increase in CARD10 (caspase recruitment domain-10)/ CARMA3 (Fig. 1C). CARD10 is known to activate NF-кB through BCL10, a component of the NF- $\kappa \mathrm{B}$ cascade that functions upstream of IкB kinase- $\beta$ (IKK $\beta)(29,30)$. BCL10 
Table I. Enriched BRAF-dependent functional categories.

\begin{tabular}{lcc}
\hline Functions & Genes & Significance \\
\hline Cell growth and proliferation & 58 & $6.48 \mathrm{E}-4$ - 4.82E-2 \\
Cell morphology & 56 & $1.89 \mathrm{E}-4$ - 4.96E-2 \\
Cell death & 50 & $2.14 \mathrm{E}-4$ - 4.82E-2 \\
Cell cycle & 36 & $9.87 \mathrm{E}-5$ - 4.82E-2 \\
Cellular movement & 33 & $3.28 \mathrm{E}-4$ - 4.82E-2 \\
Cell-to-cell signaling & 32 & $3.49 \mathrm{E}-4$ - 4.33E-2 \\
Nervous system function & 32 & $5.17 \mathrm{E}-5-4.82 \mathrm{E}-2$ \\
Gene expression & 19 & $6.30 \mathrm{E}-4$ - 4.25E-2 \\
Immune response & 8 & $1.68 \mathrm{E}-2$ - 2.94E-2 \\
\hline
\end{tabular}

The Ingenuity analysis tool was used to determine enriched biological function categories within the dataset for changes in BRAF-dependent gene expression. The top categories are shown, along with a p-value corrected for variations in category sizes.

expression itself was also up-regulated 2.1-fold by BRAFV600E signaling in our system. Hence, our results further clarify the mechanism of NF- $\mathrm{kB}$ activation by BRAF.

Furthermore, expression of the DcR1 and DcR2 'decoy' receptors, which bind Apo2L/TRAIL (Apo2 ligand/tumor necrosis factor-related apoptosis-inducing ligand) and prevent the induction of apoptosis, were also elevated upon BRAF induction (Fig. 1C). In comparison, transcription of a structurally related gene, osteoprotegerin (OPG), was shown to be unaffected by BRAF activity (Fig. 1C). It is noteworthy that normal cells express decoy receptors, whereas cancer cells usually do not, decoy receptors were frequently detected in a large panel of cultured melanoma cells (31). Thus, in stimulating decoy receptor expression, oncogenic BRAF may contribute to the well-described resistance of melanomas to Apo2L-mediated apoptosis (31).

To uncover important facets of BRAF biology not apparent from standard microarray analysis methods (32), we have examined the genome-wide transcriptional profile of BRAF signaling in the context of other types of genomic data, including the protein-protein interaction ('interactome') map (33). Affymetrix probes showing a greater than 2-fold differential expression upon $\triangle B R A F^{\mathrm{V} 600 \mathrm{E}}$ :ER activation (representing a 0.01-713.66 range of fold change) were analyzed using the Ingenuity Pathway Analysis tool (Table I), 343 genes were eligible for creating molecular networks and mapped to 13 modules (Fig. 2, Table II). Nodes are displayed using various shapes to represent the functional class of the gene products, and the intensity of the node color indicates the degree of transcriptional up- (red) or down-regulation (grey) induced by BRAF signaling. Examples of BRAF-responsive modules include the activator protein-1 (AP-1) signaling network that includes the JUN and FBJ murine osteosarcoma viral oncogene homology (FOS) transcription factor families (Fig. 2A), inhibition of myogenic factor 3 (MYOD) to inhibit muscle cell differentiation and the commitment to myogenesis (Fig. 2B), coordinated up-regulation of the myelocytomatosis viral oncogene homolog (MYC) regulatory and effector proteins (Fig. 2C), and increased expression of proteasome (PSM) complex components to augment protein catabolism (Fig. 2D). These BRAF-associated functional modules also contain numerous genes products associated with human disease, including cancer (76 genes) and disorders of the reproductive system (34 genes), connective tissue (29 genes), neurological system (26 genes) and hematology (20). BRAF signaling may, therefore, be critical for particular aspects of network malfunctioning leading to disease phenotypes. In summary, these network analyses further our understanding of BRAF and its targets and, although these interpretations are speculative, they highlight interesting avenues for understanding the role of BRAF in various biological processes.

ERK3/MAPK6 is a target for BRAF signaling. Notably, the microarray gene expression data set showed pronounced upregulation of an atypical MAPK, extracellular signal-regulated kinase-3 (ERK3/MAPK6). As determined by normalized microarray signal intensity, ERK3 mRNA levels were substantially elevated $(\sim 10$-fold) in response to oncogenic BRAF activity compared to untreated or control cells. To validate these results, we examined the induction of ERK3 mRNA expression in the same cell system by qPCR using the ratio of ERK3 to a control RPL19 transcript (Fig. 3A). The induction of ERK3 mRNA was strongest in response to activation by $\triangle \mathrm{BRAF}^{\mathrm{V} 600 \mathrm{E}}: \mathrm{ER}$, although wild-type $\triangle \mathrm{BRAF}: \mathrm{ER}$ also significantly increased ERK3 transcription at $96 \mathrm{~h}$. The difference in the kinetics of ERK3 induction by V600E and wild-type BRAF is reflective of the elevated kinase activity associated with the mutant BRAF (5). We tested if the elevated expression of ERK3 mRNA resulted in an increase in ERK3 protein level (Fig. 3B). For this, subconfluent $\triangle \mathrm{BRAF}^{\mathrm{V} 600 \mathrm{E}}$ :ER and control cells were exposed to ethanol or to $50 \mathrm{nM} 4 \mathrm{OHT}$ in ethanol for 2-5 days and lysates from these cells were analyzed by immunoblotting. Although basal expression of endogenous ERK3 was undetectable in 3T3 cells, increased ERK3 protein levels were observed following $\triangle \mathrm{BRAF}^{\mathrm{V} 600 \mathrm{E}} \mathrm{ER}$ induction and reached a maximum at 4 days (Fig. 3B). ERK3 abundance was correlated with phosphorylation of the downstream ERK1/2 kinases. As biological and biochemical differences between the RAF isoforms have been identified using this tamoxifen-inducible system (data not shown) (34), BRAF, BRAF ${ }^{\mathrm{V} 600 \mathrm{E}}$ and RAF1 were evaluated for their ability to increase ERK3 expression (Fig. 3C). While activation of $\triangle B R A F$ :ER (Fig. 3C, lanes 2 and 3), $\triangle$ BRAF $^{\mathrm{V} 600 \mathrm{E}}$ :ER (lanes 5 and 6) and $\triangle$ RAF1:ER (lanes 8 and 9) promoted ERK3 accumulation, the previously reported differences between RAF isoforms in terms of catalytic activity and downstream ERK1/2 phosphorylation $(21,34)$ is reflected in the relative abilities of these kinases to increase ERK3 protein levels. Taken together, these results indicate that constitutive BRAF/ RAF1 signaling and ERK1/2 activation leads to a dramatic elevation of ERK3 transcript and protein levels compared to control cells.

Previous studies have shown that ERK3 is rapidly targeted for ubiquitin-mediated degradation (35). Hence, we analyzed whether attenuation of this mechanism might also contribute to the BRAF-mediated accumulation of ERK3 in our cell lines. To test this hypothesis, we measured the half-life of endogenous ERK3 after pharmacological inhibition of activated, 
A

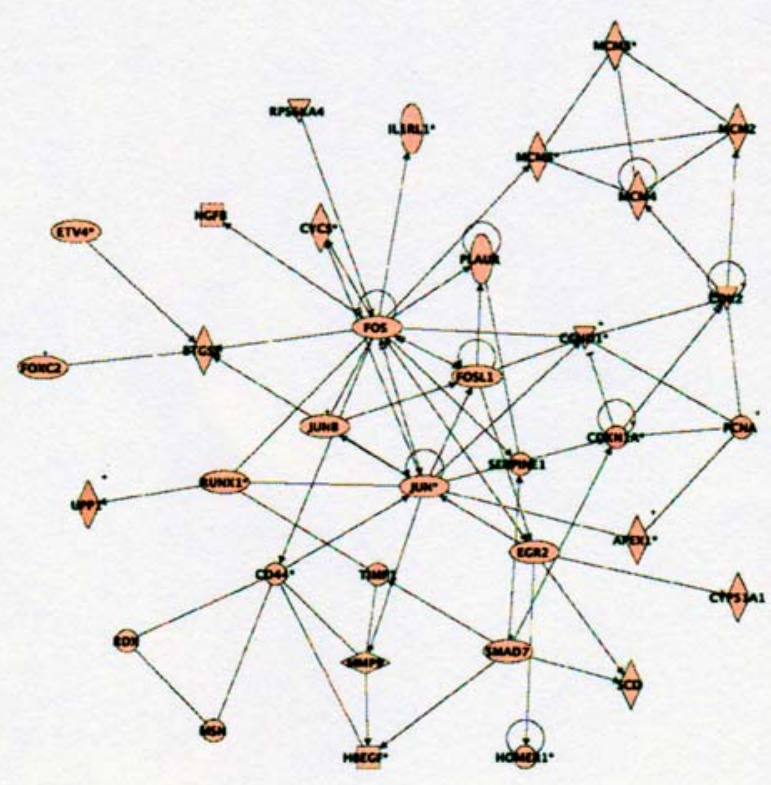

B

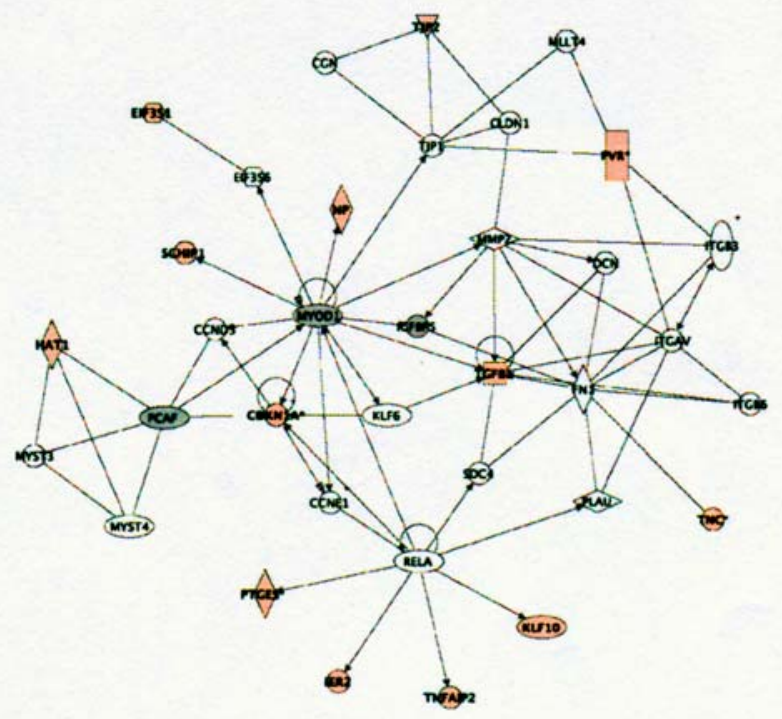

C

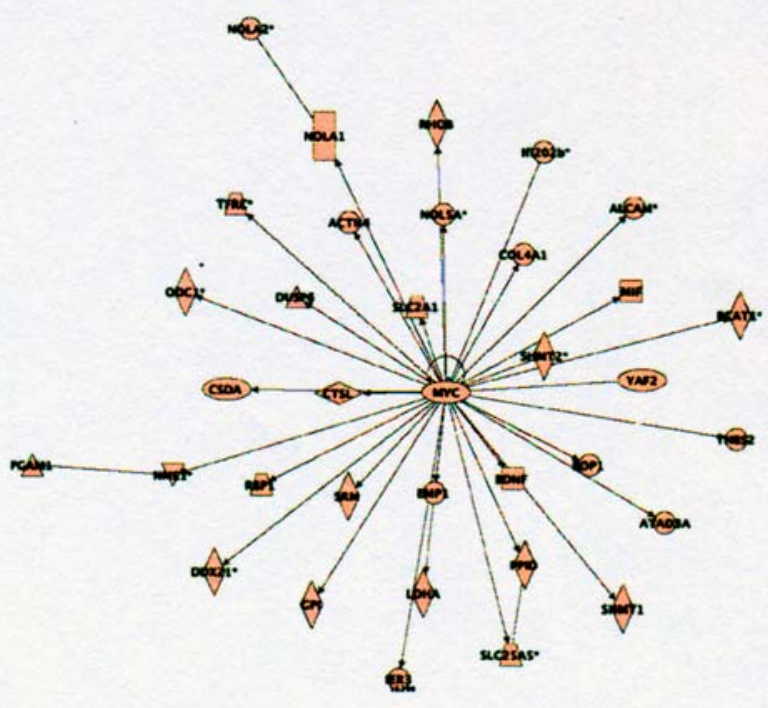

D

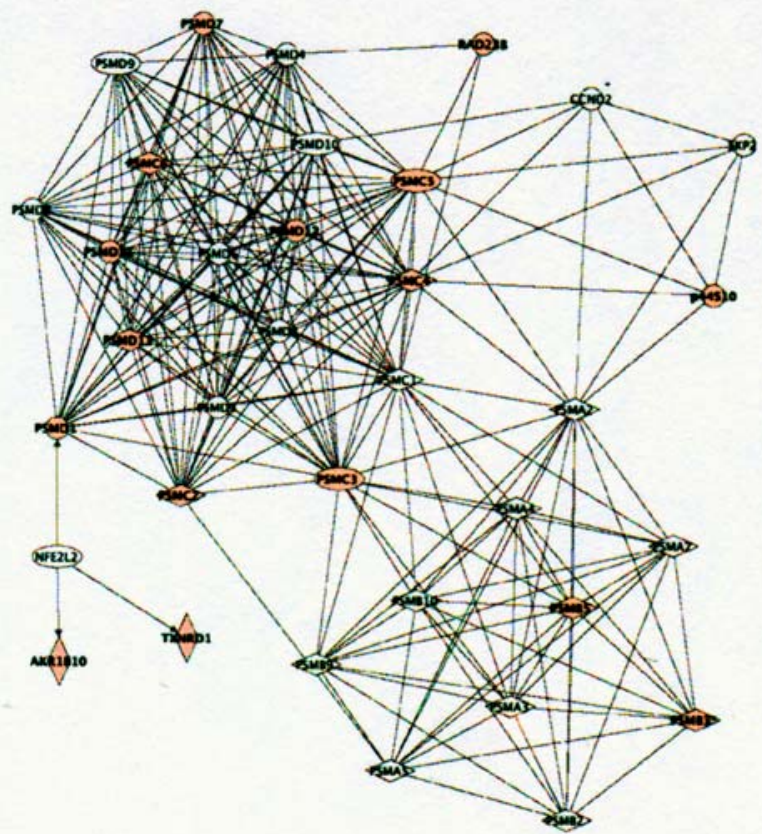

Figure 2. Network representation of biological processes underlying the response to oncogenic BRAF signaling. Networks are displayed graphically as nodes (genes/gene products) and edges (the biological relationships between the nodes). Intensity of the node color indicates the degree of up- (red) or downregulation (grey) for the (A), FBJ murine osteosarcome viral oncogene homology (FOS); (B), myelocytomatosis viral oncogene homolog (MYC); (C), myogenic factor 3 (MYOD); and (D), proteosome (PSM) networks. Nodes are displayed using various shapes that represent the functional class of the gene product (square, cytokine; triangle, kinase or phoshatase; horizontal oval, transcription regulator; vertical oval, transmembrane receptor; rectangle, nuclear receptor; diamond, enzyme; rhomboid, transporter; hexagon, translation factor; circle, other). The length of an edge reflects the evidence supporting the nodeto-node relationship. Bold genes are those identified by BRAF microarray analysis. A score of $>3$ is considered statistically significant. ${ }^{+}$Genes that appear in $>1$ network. *Nodes that have been represented in expression data more than once.

tamoxifen-stimulated $\triangle \mathrm{BRAF}^{\mathrm{V} 600 \mathrm{E}}$ :ER with BAY 43-9006 (36). Treatment with $10 \mu \mathrm{M}$ BAY 43-9006 was found to rapidly and potently diminish ERK1/2 phosphorylation (Fig. 3D, upper panel). No change in the abundance of total ERK1/2 was observed under these conditions. In contrast, ERK3 protein was highly unstable following $\triangle \mathrm{BRAF}^{\mathrm{V} 600 \mathrm{E}}$ :ER inhibition, with a half-life of approximately $15 \mathrm{~min}$. Similar kinetics of ERK3 degradation was also observed when BRAF signaling was maintained concomitant with inhibition of protein synthesis by cycloheximide treatment (Fig. 3D, lower panel). 
Table II. BRAF-regulated protein-protein interaction networks identified using Ingenuity Pathways Analysis and knowledge base.

\begin{tabular}{cc}
\hline Network & Genes in network \\
\hline \multirow{2}{*}{1} & ACTN4, ALCAM, ATAD3A, BCAT1, BDNF, BOP1, COL4A1, CSDA, CTSL, DDX21, DUSP6, \\
& EMP1, GPI, IER3, Ifi202b, LDHA, MIF, MYC, NME1, NOL5A, NOLA1, NOLA2, ODC1, \\
& PGAM1, PPID, RBP1, RHOB, SHMT1, SHMT2, SLC25A5, SLC2A1, SRM, TFRC, THBS2, YAF2 \\
& \\
& APEX1, CCND1, CD44, CDK2, CDKN1A, CYCS, CYP51A1, EGR2, ETV4, FOS, FOSL1, FOXC2, \\
& HBEGF, HOMER1, IL1RL1, JUN, JUNB, MCM2, MCM3, MCM4, MCM5, MMP9, MSN, \\
& NGFB, PCNA, PLAUR, PTGS2, RDX, RPS6KA4, RUNX1, SCD, SERPINE1, SMAD7, TIMP1, UPP1
\end{tabular}

3 AARS, ACSL4, AHCY, BIK, C1QBP, CASP3, CEACAM1, CTPS, EIF2S1, EIF4EBP1, EIF4G1, ETF1, EXOSC6, GARS, GSPT2, GTPBP4, HAN11, IARS, KCTD3, LMO7, LSM8, MCL1, MIG-6, NOLC1, PABPC1, PHLDB2, PSME3, RAI14, SLK, UNC5B, VIM, YWHAD, YWHAG, YWHAZ, ZFP36

4 ATAD2, CACYBP, CD9, CDK6, CDKN1A, CDKN2A, CDKN2C, CTCF, CTSB, DCK, DHFR, DMTF1, E2F1, E2F3, E4F1, GPCR5A, HMGA2, ITGA5, ITGA6, ITGB3, ITGB5, MAC30, MYC, ODC1, PBX3, PCGF2, PHC2, PSAT1, RPL9, S100A6, TBX3, TFDP1, TOPBP1, TYMS, ZBTB17

5 AKAP2, AKAP11, BARD1, BRCA1, C12orf14, CCNB1, CDKN1A, CSTF1, CSTF2, DLG1, E2F4, E2F5, FNBP3, GADD45A, GADD45B, IER5, JUNB, JUND, MEP50, MPP6, MTHFD1, NEK2, PIAS3, PLSCR1, PRKAR2A, RNF11, SKB1, SMAD2, SMAD4, SMAD7, SNRPD3, SSX2IP, STAMBP, TEAD4, VEGF

6 APEX1, BAG2, CDC25C, CDK4, CDKN1A, CSTF1, DKK1, DUSP4, EGR3, ETV1, FASLG, GADD45A, GNL3, HES1, HSPA8, HSPH1, IFI16, JMJD1C, LRP5, MAP2K3, MAPK3, MAPK8, MAPK11, MAPK14, MAPKAPK2, MCL1, MSH3, PCNA, POLD1, POLD3, PTGS1, RGS16, RPS6KA1, SMARCB1, TP53

7 AKR1B10, CCND2, NFE2L2, p44S10, PSMA2, PSMA3, PSMA4, PSMA5, PSMA7, PSMB2, PSMB3, PSMB5, PSMB9, PSMB10, PSMC1, PSMC2, PSMC3, PSMC4, PSMC5, PSMC6, PSMD1, PSMD2, PSMD3, PSMD4, PSMD5, PSMD7, PSMD8, PSMD9, PSMD10, PSMD11, PSMD12, PSMD13, RAD23B, SKP2, TXNRD1

8 AKR1B1, APOB, ASNS, BCL2A1, CCNA1, CCND2, CCNE1, CCRK, CD14, CDK2, CDKN1A, CDT1, CEBPA, CEBPB, FOSB, HNRPAB, HP, ITGAM, KLF2, LBP, LPL, LRP8, LTF, PLOD2, PPM1F, RAB31, SF3B1, SF3B2, SF3B4, SFTPD, TM4SF1, TRIB1, UPP1, VIM, WWP1

9 AR, CEBPD, EP300, ETV5, FOXC2, FXC1, GNAI1, GNAI2, GNB1, GNB2L1, GNG5, IDH3A, IPO7, ITGB4BP, MLL, NPPB, NPR3, PA2G4, PIAS2, PIAS3, PP, PPARA, PPARBP, PPARGC1A, RAN, RANBP1, RANGAP1, SLC2A4, TIMM9, TIMM10, TIMM22, TIMM23, TIMM8A, WDR5, XPOT

10 A130040M12RIK, AATK, ABCE1, ACTB, ANKH, ATP2B1, ATP6V0D1, CCT3, CCT4, CCT5 CCT7, CCT6A, CDK5, CDK5R1, CTNNB1, EIF5, EPB41L1, FMR1, GRIN1, HSPA4, IGFBP7, ITPR1, OAZIN, OGDH, PARK2, RPSA, SNCA, SRC, SYP, TUBA1, TUBA3, TUBA6, TUBB, UBE2G2, VAMP4

11 AK3, ANGPTL4, CCL8, CCND1, CDKN1A, CRSP2, CTDP1, EP300, EPAS1, ERCC1, ERCC4, ERCC5, ESR2, GOT1, ID1, NCOA1, NCOA2, NCOA3, NCOR1, NR1H3, NR3C2, PEPD, PGR PIAS2, PPARBP, PPARG, RORA, SOX9, SREBF1, STAT5A, TACC2, THRA, UCK2, XPA, ZRF1

12 ABL1, ADRB2, BCR, BTC, CBLB, CEACAM1, EGFR, ERBB3, ERBB4, EREG, GRASP, GRM1, GRM5, HSPCA, IRF5, ITGB3, JRK, MET, MRPL38, NASP, PBEF1, PIP5K1A, PLSCR1, PSCD2, PSCD3, PSCDBP, SAT, SH3KBP1, SHC1, SOCS5, SRC, STAT5A, SYNJ2, VAV1, VAV2

13 ARNT2, BCL2, BRCA1, CAPG, CAV1, ELL2, GDNF, GLI1, GPC1, HDAC1, HDAC2, HMGA1, IDI, IFRD1, IL2RA, INSIG1, INSR, KLF9, LRRFIP1, NFATC2, NGEF, NRG1, PLCB1, POLD4, PRKCA, SAP18, SIM1, SIN3A, SIN3B, SLIT2, SP1, TNFRSF9, TNFSF9, TSC22D1, VEGF

14 CCND3, CCNE1, CDKN1A, CGN, CLDN1, DCN, EIF3S1, EIF3S6, FN1, HAT1, IER2, IGFBP5, ITGAV, ITGB3, ITGB6, KLF6, KLF10, MLLT4, MMP2, MYOD1, MYST3, MYST4, NP, PCAF, PLAU, PTGES, PVR, RELA, SCHIP1, SDC4, TGFB1, TJP1, TJP2, TNC, TNFAIP2

15 AZI2, BCL10, CARD10, CDC37, CHUK, DDX39, EGFR, GRB2, HARS, HSPCAL3, HSPCB, IKBKAP, IKBKB, IKBKE, IKBKG, MALT1, MAP3K14, NCOA3, NFKB1, NFKB2, PRNP, PTPN12, RAB6IP2, RALGPS1, SGK, SHC1, SRC, STIP1, TBK1, TOMM7, TOMM20, TOMM22, TOMM34, TOMM40, TOMM70A

16 BRAF, CAV1, CDC37, ERBB2, GJA1, GRB10, GRIN1, HK2, IGF2, IL11, IL11RA, IL13RA1, IL6ST, INSR, IRS1, JAK1, KIAA0802, LYN, MARK4, MYBBP1A, MYO10, NCOA3, PRKCD, PRKCE, PRKCI, PTPRE, RAF1, SPRED1, SPRY2, SPRY4, SRC, STAT3, SYNCRIP, TYK2, YWHAH

Score Network function

50 Cell death, connective tissue disorders, tissue morphology

50 Cell death, proliferation, DNA replication, recombination and repair

35 Protein synthesis, cell death, connective tissue disorders

16 Cell cycle, connective tissue development and function, cancer

16 Cell cycle, connective tissue development and function, cellular growth and proliferation

15 Cell death, cellular growth and proliferation, DNA replication recombination and repair

13 Cancer, cell-to-cell signaling and interaction, cellular growth and proliferation

13 Cell cycle, connective tissue development and function, hematological disease

13 Cell signaling, DNA replication, recombination and repair, nucleic acid metabolism

13 Post-translational modification, protein folding, cellular assembly and organization

12 Gene expression, behavior, reproductive system development and function

11 Cell death, skeletal and muscular system, posttranslational modification

11 Cellular assembly and organization, nervous system, cellular growth and proliferation

9 Cancer, tumor morphology, cell-to-cell signaling and interaction

7 Cell death, gene expression, developmental disorder

6 Cellular growth and proliferation, cancer, amino acid metabolism 
A

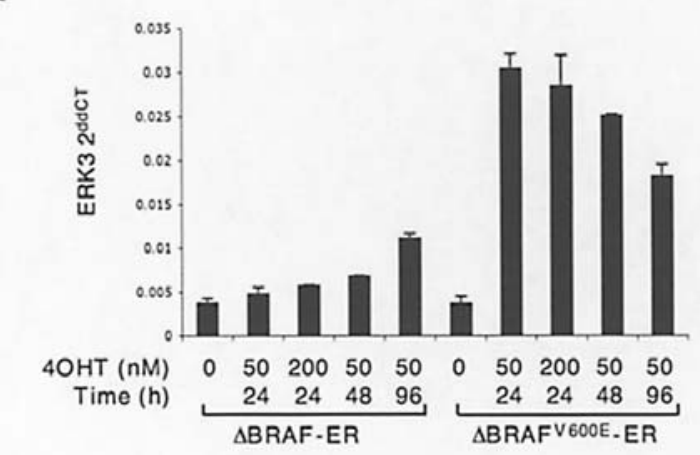

B

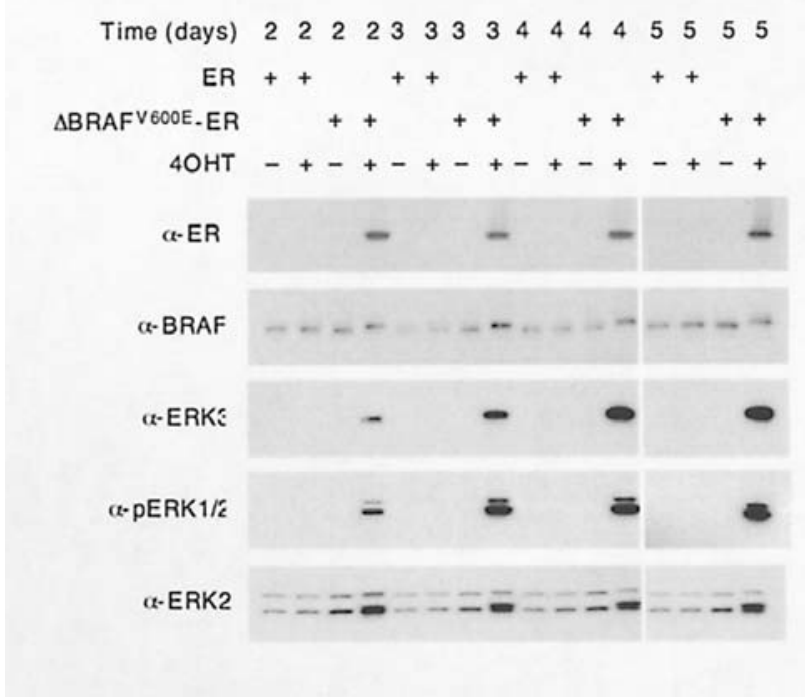

C

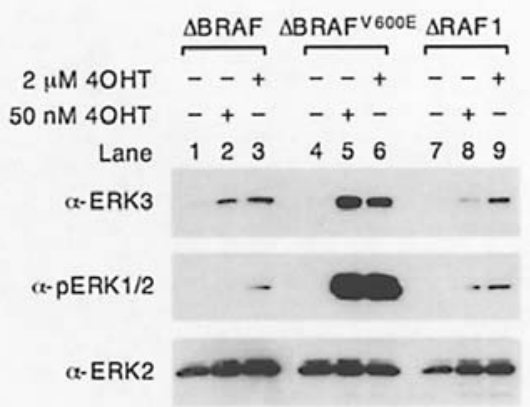

D

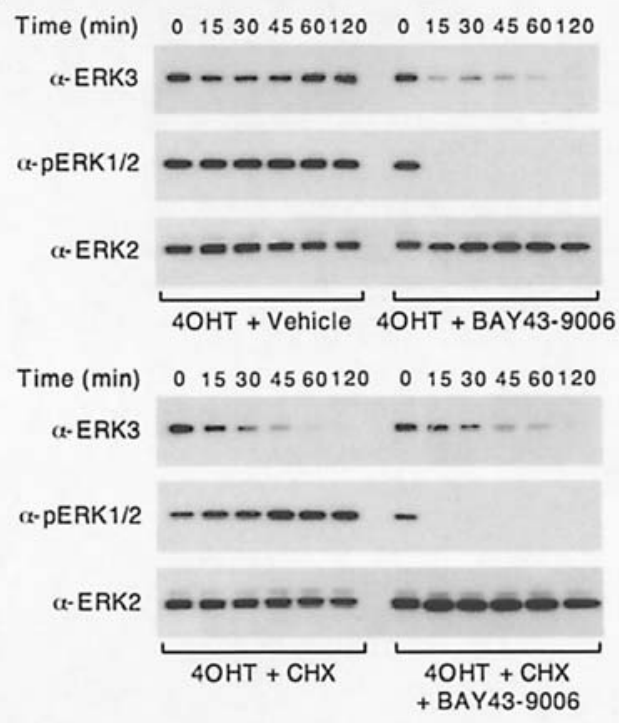

Figure 3. Induction of ERK3 expression in NIH $3 \mathrm{~T} 3$ cells by oncogenic BRAF proteins. (A), 3T3 cells expressing the wild-type and V600E forms of $\triangle B R A F: E R$ were either untreated or treated with 50 or $200 \mathrm{ng} / \mathrm{ml} 4$ OHT plus supplements for 24,48 or $96 \mathrm{~h}$ as indicated. Cells were harvested and total RNA was isolated. TaqMan qPCR measurements of ERK3 and RPL19 (internal reference) mRNA levels were carried out as described in Materials and methods. Results are reported as the mean $\pm \mathrm{SD}$ of three independent experiments. (B), Activation of $\triangle \mathrm{BRAF}{ }^{\mathrm{V} 600 \mathrm{E}}$ :ER leads to accumulation of ERK3 protein. The relative abundance of ERK3 protein in extracts of $\triangle \mathrm{BRAF}^{\mathrm{V} 600 \mathrm{E}}$ :ER treated with $4 \mathrm{OHT}$ for 2-5 days was determined by immunblotting. Membranes were then reprobed with antibodies recognizing the $\triangle \mathrm{BRAF}$ :ER fusion protein, endogenous BRAF, phospho-ERK1/2 and total ERK2. Decreased electrophoretic mobility of endogenous BRAF and phosphorylation of ERK1/2 are indicative of pathway activation resulting from each treatment. (C), ERK3 protein expression and ERK1/2 phosphorylation by $\triangle \mathrm{BRAF}: \mathrm{ER}, \triangle \mathrm{BRAF}^{\mathrm{V} 600 \mathrm{E}}$ :ER and $\triangle \mathrm{RAF} 1$ :ER induction with either $2 \mu \mathrm{M}$ or $50 \mathrm{nM} 4 \mathrm{OHT}$ were measured by immunoblotting of whole cell lysates. Equivalent loading was confrmed by probing the blots for total ERK2. (D), Oncogenic BRAF signaling does not alter ERK3 degradation. $\triangle \mathrm{BRAF}^{\mathrm{V} 600 \mathrm{E}}$ :ER cells were induced with $50 \mathrm{nM} 4 \mathrm{OHT}$ for $18 \mathrm{~h}$ and then treated with $10 \mu \mathrm{M}$ BAY $43-9006$ (RAF kinase inhibitor) and $100 \mu \mathrm{g} / \mathrm{ml}$ cycloheximide (CHX) as indicated. Cells were harvested at 0, 15, 30, 60, 120 and 240 min time points and protein lysates analyzed for ERK3 protein levels.

These results show that BRAF activity exclusively regulates the expression of ERK3 without affecting proteasome-mediated turnover of ERK3 protein.

ERK3/MAPK6 expression in melanoma. To more directly address the regulation of ERK3 expression by BRAF signaling we infected A375 melanoma cells, which have an endogenous $\mathrm{BRAF}^{\mathrm{V} 600 \mathrm{E}}$ allele, with a retrovirus expressing either BRAFspecific shRNAs or a control firefly Luciferase shRNA (20). In this system, the Tet repressor protein binds a modified polIII promoter, thereby preventing shRNA expression. However, in the presence of a tetracycline analog, doxycycline (Dox), the Tet repressor protein is released from the promoter resulting in shRNA transcription and knockdown of endogenous BRAF or luciferase expression. Consistent with the conclusions derived from the $\triangle \mathrm{BRAF}{ }^{\mathrm{V} 600 \mathrm{E}}$ :ER cells, Doxinduced shRNA-mediated BRAF knockdown resulted in a concomitant reduction of ERK3 levels and phosphorylated ERK1/2, while total ERK2 levels remained unchanged (Fig. 4A). Similar results were obtained with two BRAFspecific shRNAs, supporting that these data result from gene silencing of the BRAF target gene and not from unintended, off-target transcripts (Fig. 4A, lane 4). As expected, in A375 cells expressing a control shRNA directed against Luciferase, Dox addition did not alter ERK3 abundance (Fig. 4A, lane 6). Taken together, this indicates that ERK 3 expression can be abrogated in these melanoma cells by suppression of endogenous oncogenic BRAF.

We next carried out experiments to identify the BRAF downstream signals that are important for ERK3 expression. 
A

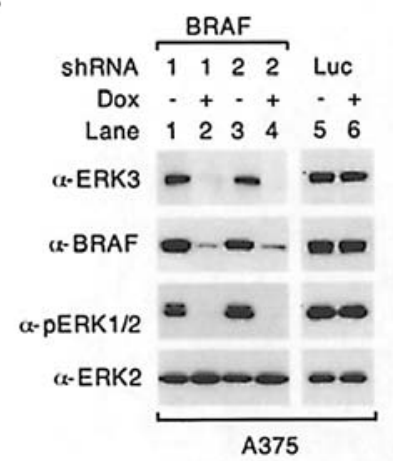

B

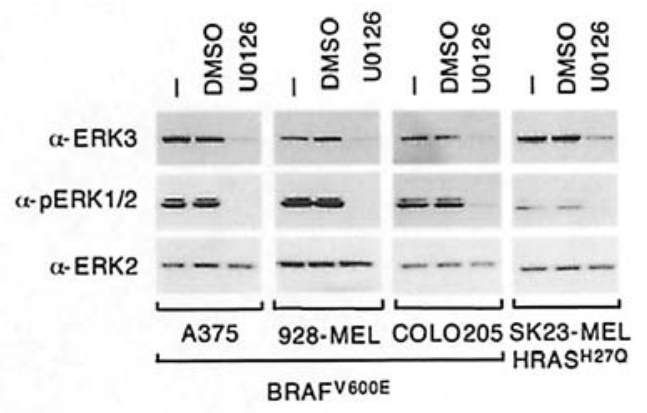

D

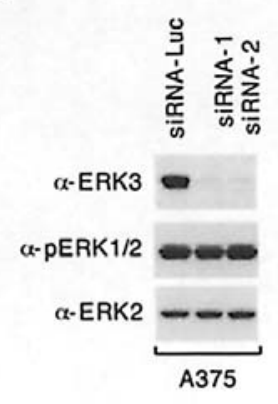

E

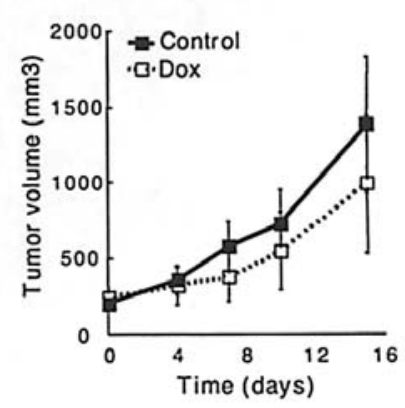

Figure 4. Changes in ERK3 expression induced by oncogenic BRAF are dependent on BRAF and MEK activity. (A), shRNA-mediated knockdown of BRAF leads to loss of ERK1/2 activity and ERK3 expression. A375 cell clones stably expressing BRAF shRNAs or control Luciferase (Luc) shRNA were treated with $2 \mu \mathrm{g} / \mathrm{ml}$ doxycycline (Dox) for $72 \mathrm{~h}$. Lysates were then analyzed by immunoblotting. (B), Activated ERK1/2 signaling positively regulates the accumulation of ERK3 in a variety of human cancer cell lines. A375 (melanoma, BRAF ${ }^{\mathrm{V} 600 \mathrm{E}}$ ), 928-MEL (melanoma, BRAF ${ }^{\mathrm{V} 600 \mathrm{E}}$ ), SK23-MEL (melanoma, H-RAS ${ }^{\mathrm{H} 27 \mathrm{Q}}$ ) and COLO 205 (colon cancer, BRAF ${ }^{\mathrm{V} 600 \mathrm{E}}$ ) cells were treated with the MEK1/2 inhibitor, U0126, at $10 \mu \mathrm{M}$ for $24 \mathrm{~h}$. Downstream ERK1/2 phosphorylation and ERK3 protein abundance were evaluated by immunoblotting. (C), p38 MAPK signaling does not mediate ERK3 stabilization in A375 melanoma cells. A375 cells were treated with $10 \mu \mathrm{M}$ of either p38 MAPK inhibitor (SB203580) or MEK1/2 inhibitor (U0126) for either 2.5 or $24 \mathrm{~h}$. Cytoplasmic lysates were assayed for expression of ERK3, phosphorylated ERK1/2, and the mobility shift of MAPKAPK2 (MK2) to its phosphorylated form as a read-out for p38 MAPK signaling activity. As a positive control for small molecule inhibition of p38 MAPK, pretreatment of cells with SB203580 for $2 \mathrm{~h}$ was sufficient to prevent p38 MAPK activation induced by a strong p38 MAPK agonist, anisomycin (Aniso; $10 \mu \mathrm{g} / \mathrm{ml}$ for $15 \mathrm{~min}$ ). (D), Transient transfection of ERK3-specific siRNAs (siRNA-1 and siRNA-2) did not alter protein expression of activation of ERK1/2 as determined by immunoblotting. Luciferase-specific siRNA (siRNA-Luc) was used as a control. (E), ERK3 shRNA knockdown did not result in anti-tumor efficacy in A375 melanoma xenograft models. A375 inducible shRNA cells were implanted subcutaneously in the flank of athymic mice and doxycycline (Dox) was administered via drinking water as described in Materials and methods. No lethality or weight loss was observed.

A375, 928-MEL, COLO205 and SK23-MEL cell lines were characterized for BRAF and RAS activating mutations and ERK3 expression was measured by immunoblotting lysates derived from these tumors cells cultured in the presence or absence of the MEK1/2 inhibitor, U0126 (37). Treatment with $10 \mu \mathrm{M} \mathrm{U} 0126$ resulted in decreased ERK1/2 phosphorylation whereas total ERK2 levels were unaffected (Fig. 4B). Significantly, inhibition of ERK1/2 phosphorylation also abolished ERK3 expression. Thus, ERK3 induction in melanoma cells requires activation of BRAF downstream signaling to the MAPK pathway component, MEK1/2.

It has been reported that cellular ERK3 accumulation is dependent on p38 MAPK function (18). Hence, to investigate whether ERK3 protein up-regulation could partially be attributed to p38, we analyzed ERK3 levels in A375 cells in the presence or absence of a selective p38 MAPK inhibitor, SB203580 (38). While induction of ERK3 expression was completely blocked by preventing ERK1/2 activation via the U0126 MEK1/2 inhibitor, treatment with SB203580 failed to destabilize ERK3 in these cells (Fig. 4C). As a control, activation of p38 MAPK downstream signaling in cell lysates was assessed by electrophoretic mobility shift of phosphorylated MAPKAPK2 (MK2), a direct kinase substrate of p38 MAPK, using a potent agonist of p38 activity, anisomycin. These results are in agreement with recent work showing that p38 MAPK signaling did not affect ERK3 localization (15) and suggests regulation of ERK3 by p38 MAPK may be cell type-dependent.

To investigate the biological consequences of ERK3 expression in melanoma, we utilized RNA interference to disrupt endogenous ERK3 expression in A375 cells. ERK3specific siRNAs efficiently suppressed ERK3 protein levels without affecting ERK1/2 abundance or activation (Fig. 4D). From these validated oligonucleotide sequences, stable cells that express ERK3 inducible-shRNA were generated to determine whether depletion of ERK3 would affect the ability of A375 cells to form tumors in vivo (20). Mice bearing inducible-shRNA xenografted tumors were administered either $5 \%$ sucrose or $1 \mathrm{mg} / \mathrm{ml}$ doxycycline plus $5 \%$ sucrose and monitored for tumor progression. Loss of ERK3 did not 
significantly alter A375 tumor growth (Fig. 4E). Furthermore, there was no clear histological evidence of changed tumor cell proliferation, apoptosis or angiogenesis upon ERK3 knockdown as determined by immunohistochemical staining of Ki-67, cleaved caspase-3 and MECA-32, respectively (data not shown). Taken together, elucidating the physiological significance of BRAF-mediated ERK3 induction will require further examination in additional models or biological systems.

\section{Discussion}

A better understanding of the molecular alterations elicited by activating BRAF mutations is critical to assess the contribution of this oncogene to melanoma progression. Our integrative analysis of the complete BRAF-dependent transcriptome in $3 \mathrm{~T} 3$ cells provides new insight into the diverse array of signaling changes elicited by oncogenic BRAF. Many of the targets we have identified have largely unknown functions, whereas others are known to be involved in metabolism, gene regulation, growth responsiveness, cell adhesion, immunity, apoptosis and angiogenesis. Several structural protein categories are also represented, including DNA-binding, protein phosphorylation and signal transduction. For a selected group of genes, real-time qPCR was used to validate the microarray expression data (Fig. 1). In particular, the atypical kinase ERK3/MAPK6 showed distinct overexpression in response to BRAF signaling and was verified by inducible $\triangle B R A F^{V 600 E}$ :ER 3T3 cells (Fig. 3) and inducible shRNAmediated BRAF knockdown in A375 melanoma cells (Fig. 4A). In this context, ERK3 induction is dependent on signaling through MEK1/2 (Fig. 4B), the kinases immediately downstream of BRAF, and does not require p38 MAPK activation (Fig. 4C). The requirement of ERK1/2 in ERK3 induction still remains to be investigated. Taken together, although accumulating evidence point to ERK3 biological activity being mainly controlled by regulated turnover, our results provide a novel mechanism by which ERK3 signaling can be modulated.

To date, efforts to understand the physiological function of ERK3 have been hampered by the inability to detect exogenously expressed wild-type ERK3 in most cell lines (data not shown) (35). Large amino-terminal tags have been used to circumvent this technical issue and disrupt the normal ubiquitin-mediated regulation of the protein (39). However, the non-physiological overexpression of stabilized ERK3 may confound the results of these experiments. As suggested herein, it may be advantageous to utilize the RAF activation system as a means of up-regulating endogenous ERK3 levels to study its biological functions.

In summary, our results provide insight into the global gene expression profile of BRAF activation and highlight the cellular circuits employed by BRAF that are crucial to its biological activity in normal and disease settings. Furthermore, we have provided evidence linking ERK3 expression to oncogenic BRAF signaling in melanoma. In this tumor type, ERK3 protein levels are contingent on activation of the BRAF-directed transcriptional program. Interestingly, ERK3 is also expressed in gastric cancer (40) and in a mouse model for salivary gland tumorigenesis (41). The extent to which ERK3 expression is linked to constitutive BRAF signaling in these tumor types and the possible utility of ERK3 as a pharmacodynamic marker for BRAF activity requires further evaluation.

\section{Acknowledgements}

We thank Karen Toy, Suzie Scales, Gladys Ingle, Si Tuen Lee-Hoeflich, Kanan Pujara, Bijay Jaiswal, Josh Kaminker, Johnny Gutierrez, Gloria Meng, Janeko Bower, Angela McNutt, Leslie Lee, Sandy Adams, Ursula Vitt, Mark Vasser, Qiang $\mathrm{Xu}$, Tom $\mathrm{Wu}$ and members of the Seshagiri lab for their technical assistance, and Vishva Dixit for helpful discussions.

\section{References}

1. American Cancer Society: Cancer Facts and Figures 2005. American Cancer Society, Atlanta, 2005.

2. Thompson JF, Scolyer RA and Kefford RF: Cutaneous melanoma. Lancet 365: 687-701, 2005.

3. Davies H, Bignell GR, Cox C, Stephens P, Edkins S, Clegg S, Teague J, Woffendin H, Garnett MJ, Bottomley W, Davis N, Dicks E, Ewing R, Floyd Y, Gray K, Hall S, Hawes R, Hughes J, Kosmidou V, Menzies A, Mould C, Parker A, Stevens C, Watt S, Hooper S, Wilson R, Jayatilake H, Gusterson BA, Cooper C, Shipley J, Hargrave D, Pritchard-Jones K, Maitland N, Chenevix-Trench G, Riggins GJ, Bigner DD, Palmieri G, Cossu A, Flanagan A, Nicholson A, Ho JW, Leung SY, Yuen ST, Weber BL, Seigler HF, Darrow TL, Paterson H, Marais R, Marshall CJ, Wooster R, Stratton MR and Futreal PA: Mutations of the BRAF gene in human cancer. Nature 417: 949-954, 2002.

4. Mercer KE and Pritchard CA: Raf proteins and cancer: B-Raf is identified as a mutational target. Biochim Biophys Acta 1653: 25-40, 2003

5. Wan PT, Garnett MJ, Roe SM, Lee S, Niculescu-Duvaz D, Good VM, Jones CM, Marshall CJ, Springer CJ, Barford D and Marais R: Mechanism of activation of the RAF-ERK signaling pathway by oncogenic mutations of B-RAF. Cell 116: 855-867, 2004.

6. Wellbrock C, Karasarides M and Marais R: The RAF proteins take centre stage. Nat Rev Mol Cell Biol 5: 875-885, 2004.

7. Sridhar SS, Hedley D and Siu LL: Raf kinase as a target for anticancer therapeutics. Mol Cancer Ther 4: 677-685, 2005.

8. Strumberg D, Richly H, Hilger RA, Schleucher N, Korfee S, Tewes M, Faghih M, Brendel E, Voliotis D, Haase CG, Schwartz B, Awada A, Voigtmann R, Scheulen ME and Seeber S: Phase I clinical and pharmacokinetic study of the Novel Raf kinase and vascular endothelial growth factor receptor inhibitor BAY 43-9006 in patients with advanced refractory solid tumors. J Clin Oncol 23: 965-972, 2005.

9. O'Neill E and Kolch W: Conferring specificity on the ubiquitous Raf/MEK signalling pathway. Br J Cancer 90: 283-288, 2004.

10. Lewis TS, Shapiro PS and Ahn NG: Signal transduction through MAP kinase cascades. Adv Cancer Res 74: 49-139, 1998.

11. Sebolt-Leopold JS and Herrera R: Targeting the mitogen-activated protein kinase cascade to treat cancer. Nat Rev Cancer 4: 937-947, 2004.

12. Bogoyevitch MA and Court NW: Counting on mitogen-activated protein kinases - ERKs 3, 4, 5, 6, 7 and 8. Cell Signal 16: 1345-1354, 2004.

13. Boulton TG, Nye SH, Robbins DJ, Ip NY, Radziejewska E, Morgenbesser SD, De Pinho RA, Panayotatos N, Cobb MH and Yancopoulos GD: ERKs: a family of protein-serine/threonine kinases that are activated and tyrosine phosphorylated in response to insulin and NGF. Cell 65: 663-675, 1991

14. Turgeon B, Saba-El-Leil MK and Meloche S: Cloning and characterization of mouse extracellular-signal-regulated protein kinase 3 as a unique gene product of $100 \mathrm{kDa}$. Biochem J 346: 169-175, 2000.

15. Seternes OM, Mikalsen T, Johansen B, Michaelsen E, Armstrong CG, Morrice NA, Turgeon B, Meloche S, Moens U and Keyse SM: Activation of MK5/PRAK by the atypical MAP kinase ERK 3 defines a novel signal transduction pathway. EMBO J 23: 4780-4791, 2004.

16. Schumacher S, Laass K, Kant S, Shi Y, Visel A, Gruber AD, Kotlyarov A and Gaestel M: Scaffolding by ERK3 regulates MK5 in development. EMBO J 23: 4770-4779, 2004. 
17. Hanks SK and Hunter T: Protein kinases 6. The eukaryotic protein kinase superfamily: kinase (catalytic) domain structure and classification. FASEB J 9: 576-596, 1995.

18. Zimmermann J, Lamerant N, Grossenbacher R and Furst P: Proteasome- and p38-dependent regulation of ERK3 expression. J Biol Chem 276: 10759-10766, 2001.

19. Coulombe P, Rodier G, Bonneil E, Thibault P and Meloche S: $\mathrm{N}$-terminal ubiquitination of extracellular signal-regulated kinase 3 and $\mathrm{p} 21$ directs their degradation by the proteasome. Mol Cell Biol 24: 6140-6150, 2004.

20. Hoeflich KP, Gray DC, Eby MT, Tien JY, Wong L, Bower J, Gogineni A, Zha J, Cole MJ, Stern HM, Murray LJ, Davis DP and Seshagiri S: Oncogenic BRAF is required for tumor growth and maintenance in melanoma models. Cancer Res 66: 999-1006, 2006.

21. Samuels ML, Weber MJ, Bishop JM and McMahon M: Conditional transformation of cells and rapid activation of the mitogen-activated protein kinase cascade by an estradioldependent human raf-1 protein kinase. Mol Cell Biol 13: 6241-6252, 1993.

22. Schulze A, Lehmann K, Jefferies HB, McMahon M and Downward J: Analysis of the transcriptional program induced by Raf in epithelial cells. Genes Dev 15: 981-994, 2001.

23. Schulze A, Nicke B, Warne PH, Tomlinson S and Downward J: The transcriptional response to Raf activation is almost completely dependent on mitogen-activated protein kinase kinase activity and shows a major autocrine component. Mol Biol Cell 15: 3450-3463, 2004.

24. Harris MA, Clark J, Ireland A, Lomax J, Ashburner M, Foulger R, Eilbeck K, Lewis S, Marshall B, Mungall C, Richter J, Rubin GM, Blake JA, Bult C, Dolan M, Drabkin H, Eppig JT, Hill DP, Ni L, Ringwald M, Balakrishnan R, Cherry JM, Christie KR, Costanzo MC, Dwight SS, Engel S, Fisk DG, Hirschman JE, Hong EL, Nash RS, Sethuraman A, Theesfeld CL, Botstein D, Dolinski K, Feierbach B, Berardini T, Mundodi S, Rhee SY, Apweiler R, Barrell D, Camon E, Dimmer E, Lee V, Chisholm R, Gaudet P, Kibbe W, Kishore R, Schwarz EM, Sternberg P, Gwinn M, Hannick L, Wortman J, Berriman M, Wood V, De la Cruz N, Tonellato P, Jaiswal P, Seigfried T and White R: The Gene Ontology (GO) database and informatics resource. Nucleic Acids Res 32: D258-D261, 2004.

25. Wiese S, Pei G, Karch C, Troppmair J, Holtmann B, Rapp UR and Sendtner M: Specific function of B-Raf in mediating survival of embryonic motoneurons and sensory neurons. Nat Neurosci 4: 137-142, 2001

26. Klagsbrun M and Eichmann A: A role for axon guidance receptors and ligands in blood vessel development and tumor angiogenesis. Cytokine Growth Factor Rev 16: 535-548, 2005.

27. Lebel-Binay S, Berger A, Zinzindohoue F, Cugnenc P, Thiounn N, Fridman WH and Pages F: Interleukin-18: biological properties and clinical implications. Eur Cytokine Netw 11: $15-26,2000$.

28. Ikenoue T, Hikiba Y, Kanai F, Tanaka Y, Imamura J, Imamura T, Ohta M, Ijichi H, Tateishi K, Kawakami T, Aragaki J, Matsumura M, Kawabe T and Omata M: Functional analysis of mutations within the kinase activation segment of B-Raf in human colorectal tumors. Cancer Res 63: 8132-8137, 2003.
29. Wang L, Guo Y, Huang WJ, Ke X, Poyet JL, Manji GA, Merriam S, Glucksmann MA, Di Stefano PS, Alnemri ES and Bertin J: Card10 is a novel caspase recruitment domain/ membrane-associated guanylate kinase family member that interacts with BCL10 and activates NF-kappa B. J Biol Chem 276: 21405-21409, 2001.

30. Zhou H, Wertz I, O'Rourke K, Ultsch M, Seshagiri S, Eby M, Xiao W and Dixit VM: Bcl10 activates the NF-kappaB pathway through ubiquitination of NEMO. Nature 427: 167-171, 2004.

31. Hersey P and Zhang XD: How melanoma cells evade trailinduced apoptosis. Nat Rev Cancer 1: 142-150, 2001.

32. Rhodes DR and Chinnaiyan AM: Integrative analysis of the cancer transcriptome. Nat Genet 37 (Suppl): S31-S37, 2005.

33. Calvano SE, Xiao W, Richards DR, Felciano RM, Baker HV, Cho RJ, Chen RO, Brownstein BH, Cobb JP, Tschoeke SK, Miller-Graziano C, Moldawer LL, Mindrinos MN, Davis RW, Tompkins RG and Lowry SF: A network-based analysis of systemic inflammation in humans. Nature 437: 1032-1037, 2005.

34. Pritchard CA, Samuels ML, Bosch E and McMahon M: Conditionally oncogenic forms of the A-Raf and B-Raf protein kinases display different biological and biochemical properties in NIH 3T3 cells. Mol Cell Biol 15: 6430-6442, 1995.

35. Coulombe P, Rodier G, Pelletier S, Pellerin J and Meloche S: Rapid turnover of extracellular signal-regulated kinase 3 by the ubiquitin-proteasome pathway defines a novel paradigm of mitogen-activated protein kinase regulation during cellular differentiation. Mol Cell Biol 23: 4542-4558, 2003.

36. Wilhelm SM, Carter C, Tang L, Wilkie D, McNabola A, Rong H, Chen C, Zhang X, Vincent P, McHugh M, Cao Y, Shujath J, Gawlak S, Eveleigh D, Rowley B, Liu L, Adnane L, Lynch M, Auclair D, Taylor I, Gedrich R, Voznesensky A, Riedl B, Post LE, Bollag G and Trail PA: BAY 43-9006 exhibits broad spectrum oral antitumor activity and targets the RAF/MEK/ERK pathway and receptor tyrosine kinases involved in tumor progression and angiogenesis. Cancer Res 64: 7099-7109, 2004.

37. Favata MF, Horiuchi KY, Manos EJ, Daulerio AJ, Stradley DA, Feeser WS, van Dyk DE, Pitts WJ, Earl RA, Hobbs F, Copeland RA, Magolda RL, Scherle PA and Trzaskos JM: Identification of a novel inhibitor of mitogen-activated protein kinase kinase. J Biol Chem 273: 18623-18632, 1998.

38. Cuenda A, Rouse J, Doza YN, Meier R, Cohen P, Gallagher TF, Young PR and Lee JC: SB 203580 is a specific inhibitor of a MAP kinase homologue which is stimulated by cellular stresses and interleukin-1. FEBS Lett 364: 229-233, 1995.

39. Julien C, Coulombe P and Meloche S: Nuclear export of ERK3 by a CRM1-dependent mechanism regulates its inhibitory action on cell cycle progression. J Biol Chem 278: 42615-42624, 2003.

40. Liang B, Wang S, Zhu XG, Yu YX, Cui ZR and Yu YZ: Increased expression of mitogen-activated protein kinase and its upstream regulating signal in human gastric cancer. World $\mathbf{J}$ Gastroenterol 11: 623-628, 2005.

41. Makitie AA, Reis PP, Arora S, Macmillan C, Warner GC, Sukhai M, Dardick I, Perez-Ordonez B, Wells R, Brown D, Gilbert R, Freeman J, Gullane P, Irish J and Kamel-Reid S: Molecular characterization of salivary gland malignancy using the Smgb-Tag transgenic mouse model. Lab Invest 85: 947-961, 2005. 